\title{
Timely launch of new journal
}

\author{
Zhibiao Liu ${ }^{1}$
}

(C) The Japan Section of the Regional Science Association International 2017

These years, the Asian-Pacific region, which is increasingly recognized as the center of global economy, has become a great contributor to global scientific research in many fields. In such process, a high-quality peer-review journal can play a significant role and constitute an important part in the dissemination of academic knowledge. The birth of Asia-Pacific Journal of Regional Science in such a period is to be congratulated!

The Yangtze River Delta area in China is one of the fastest growing economic areas in the Asian-Pacific region. It is not only a growth pole of China but also an important force driving the steady development of the world economy. Based on the international metropolis of Shanghai, it utilizes the golden opportunity of world economic development to accelerate its own growth and thus has generated three distinctive but interconnected development models: the modern-service-oriented internationalized city development model of Shanghai; the FDI-based exportoriented open development model of Jiangsu; and the endogenous economic development model, characterized by businesses owned and managed by the people and for the people, of Zhejiang. Shanghai's modern service industry reduces its institution cost and transaction cost while Jiangsu and Zhejiang are the center of manufacture cost reduction. Together, they greatly raise the industrial competitiveness of the Yangtze River Delta economic zone.

To study and disseminate these regions' experience, however, it is necessary to ascend to the theoretical level, carry out international comparisons and learn from international experience and theoretical guidance. I hope that Asia-Pacific Journal of Regional Science can become a high-level journal in terms of studying and disseminating the economic development experience of the Asian-Pacific region!

Zhibiao Liu

zbliu@nju.edu.cn

1 Research Center for the Yangtze River Delta Economic and Social Development, Nanjing University, Nanjing, China 